\title{
The Impact of Human Capital on the Beijing Economic Growth
}

\author{
L.L.HOU \& X.J. WANG \\ School of Humanities and Social Sciences of Beihang University, Beijing, China
}

\begin{abstract}
By regression analysis of relevant data in Beijing from 1993 to 2013, this article tries to figure out that the impact of Beijing's human capital investment growth for its economic growth. The empirical result shows that Beijing's economic growth based on the common growth of its physical capital and human capital. However, from the current development trend, it shows that investment in human capital of Beijing for its role in promoting Beijing's economic growth will be larger than physical capital investment. According to the empirical result, we finally make a few suggestion that maintain physical capital inputs of Beijing to ensure the steady growth of its economy in the foreseeable future years, at the same time, further increase human capital investment of Beijing to actively encourage its rapid economic growth.
\end{abstract}

KEYWORD: Beijing; Human Capital; Economic Growth; Empirical Analysis

\section{INTRODUCTION}

International research on the relationship between human capital and economic growth has experienced a continuous process of exploration, the new growth theory represented by Lucas and Romer created a new stage of economic growth research. The prospects for constructing a neoclassical theory of growth was considered by Lucas (1988), and three models of emphasizing physical capital accumulation, human capital accumulation through schooling and specialized human capital accumulation through learning by doing were compared to evidence. A theoretical framework for thinking about the role of human capital in a model of endogenous growth was outlined by Romer (1990), and it found that the initial level of human capital like literacy does help predict the subsequent rate of investment and the rate of growth. The impact of human capital on the process of economic growth was investigated by Savvides et al. (2006), through deriving estimates of the output elasticity and social return to human capital for 51 countries at various stages of economic development. The power of the human capital hypothesis to explain observed differences in long term growth dynamics across specific countries was illustrated by Ehrlich(2009), which is in the case that the emergence of the US as the world economic superpower, overtaking the UK and Europe in general.
For Chinese scholars, most of them were more focused on empirical research, and tried to find out the relationship between human capital and economic growth from the perspective of the country or region rather than city. The view hold by Tang (2006) was that the increasing of human capital marginal returns does promote the sustained economic growth. A model of endogenous growth was constructed by Yang (2006), and empirical analyzed the impact of human capital accumulation and formation elements of human capital on the economic growth. Compared with the east and western region of China, Wang \& Zheng (2010) pointed out that human capital plays a specific role in economic growth in different regions, and could be the reason that the level of the economic development between different regions is different. Various human capital indexes were constructed by Li et al. (2010), which measured with modified Jorgenson-Fraumeni lifetime income approach, and made projections up to 2020 .

Until now, there are still many scholars dedicated to study the relationship between human capital and economic growth using different approach and transforming different perspective. Due to Beijing, as the capital of China, possess the most abundant human capital, this article tries to concentrate on the impact of human capital on the Beijing economic growth, and expects to provide a reference for the development of relevant policies after compared with the impact of physical capital. 


\section{MODEL AND DATA}

\subsection{Model}

In this article, Cubb-Douglas production function is used to analysis the impact of human capital on the Beijing economic growth. As follow:

$$
Y=A K^{\alpha} L^{\beta}
$$

Where $Y$ =output; $A=$ technological advances; $K=$ physical capital investment; $L=$ human capital investment; $\alpha=$ elasticity of physical capital; $\beta=$ elasticity of human capital.

\subsection{Index Selection}

For index of output, real GDP is used to measure of economic growth in case that excluding the effect of inflation, which equals to nominal GDP divided by the GDP index. For index of physical capital investment, actual total investment in fixed assets is considered to reflect the scale of investment in fixed assets for eliminating the effect of inflation, which is equal to nominal total investment in fixed assets divided by fixed assets investment value index. For index of human capital investment, actual human capital is think of reflecting long-term human capital that calculated by J-F approach, which is equivalent to nominal human capital divided by CPI index. In addition, J-F approach is come from the study of Jorgenson and Fraumeni, who are dedicated to the research of human capital accumulation.

\subsection{Data Source}

Based on the data released by the China's National Bureau of Statistics website, all relevant data from 1993 to 2013 is selected to be used, excluding the data of nominal human capital. In addition, the data of nominal human capital from 1993 to 2010 is cited from database of China Center for Human Capital and Labor Market Research. But for the data of nominal human capital from 2011 to 2013, which has not calculated, this article tries to superimpose the average growth rate of nominal human capital onto the nominal human capital of the last year. As Table 1 below.

Table 1. The Value of Index (Unit: 100 Million)

\begin{tabular}{|c|c|c|c|}
\hline Year & Output & Physical Capital Investment & Human Capital Investment \\
\hline 1993 & 7.89 & 3.24 & 143.90 \\
\hline 1994 & 10.07 & 5.58 & 155.54 \\
\hline 1995 & 13.46 & 7.39 & 190.90 \\
\hline 1996 & 16.41 & 8.10 & 235.82 \\
\hline 1997 & 18.87 & 9.36 & 292.37 \\
\hline 1998 & 21.71 & 11.16 & 356.29 \\
\hline 1999 & 24.16 & 11.72 & 421.67 \\
\hline 2000 & 28.28 & 12.68 & 489.72 \\
\hline 2001 & 33.20 & 15.04 & 576.36 \\
\hline 2002 & 38.70 & 17.89 & 721.25 \\
\hline 2003 & 45.07 & 21.23 & 845.50 \\
\hline 2004 & 52.88 & 24.24 & 997.79 \\
\hline 2005 & 62.17 & 28.08 & 1143.15 \\
\hline 2006 & 71.84 & 32.83 & 1501.21 \\
\hline 2007 & 86.00 & 38.01 & 1868.55 \\
\hline 2008 & 101.88 & 35.39 & 2266.03 \\
\hline 2009 & 110.28 & 47.55 & 2987.61 \\
\hline 2010 & 127.96 & 52.71 & 3402.34 \\
\hline 2011 & 150.34 & 52.78 & $3941.45^{*}$ \\
\hline 2012 & 166.01 & 60.34 & $4813.50 *$ \\
\hline 2013 & 181.06 & 68.54 & $5750.45^{*}$ \\
\hline
\end{tabular}

* Source: Author's calculation

\section{EMPIRICAL ANALYSIS}

\subsection{The regression result}

Before OLS regression, Augmented Dickey-Fuller test and Johansen test are carried out based on the logarithmic transformed data, and indicates that there exist a stable equilibrium relationship between the variables so that OLS regression could be performed. As follow ( $\mathrm{t}$ test values are in parentheses): 
$\ln Y=-0.737965+0.506130 \ln \mathrm{K}+0.445706 \ln \mathrm{L}$

$$
\text { (-4.69) (6.76) }
$$

$$
R^{2}=0.997772 \quad F=4030.828 \quad D . W .=2.224698
$$

From the regression result, it is illustrated that the data is well fitted the model, and it is obviously that the model shows a significant linear relationship between variables.

\subsection{Result analysis}

Foremost, Beijing's economic growth based on the common growth of its physical capital and human capital. According to the regression result, under the significance level of $1 \%$, t test values of $\ln K$ and $\ln L$ are more than 2.878 in case that the number of variables transformed freely is 18 , moreover $\alpha$ and $\beta$ are positive number, it is reasonable that investment growth of Beijing's physical capital and human capital promoted its economic growth at the same time and place.

Secondly, the impact of Beijing's physical capital investment growth on its economic growth is greater than human capital. On the basis of the regression result, $\alpha$ and $\beta$ are 0.506130 and 0.445706 respectively, it means that each additional unit of physical capital investment brings about 0.506130 unit growth of economic, which is more than human capital by 0.060424 unit. It is considered that Beijing's physical capital investment growth plays an important role in creating its economic growth more than human capital.
Finally, from the current development trend, investment in human capital of Beijing for its role in promoting Beijing's economic growth will be larger than physical capital investment. According to Figure 1, the annual growth rate of Beijing's human capital investment is higher than physical capital investment in most of the years from 1993 to 2013, which is maintained rising trend continuously. And it can be seen from Table 2 that the annual average growth rate and the impact rate on real GDP of Beijing's human capital are $20.25 \%$ and $9.03 \%$ respectively, which is slightly larger than physical capital. With the current trend, there is no doubt that the investment of human capital for stimulating Beijing's economic growth will be more considerable than physical capital investment.



Figure 1 The Annual Growth Rate* from 1993 to 2013

* The annual growth rate is calculated by a formula, where $X=$ the value; $n=$ current year. As follow:

$\left[\left(X_{n}-X_{n-1}\right) / X_{n-1}\right] \times 100 \%$

Table 2. The Annual Average Growth Rate and Impact Rate on Real GDP.

\begin{tabular}{|c|c|c|}
\hline & The Annual Average Growth Rate* & Impact Rate on Real GDP* \\
\hline Physical Capital Investment & $16.48 \%$ & $8.34 \%$ \\
\hline Human Capital Investment & $20.25 \%$ & $9.03 \%$ \\
\hline
\end{tabular}

* The annual average growth rate is equal to geometric growth rate, and multiplied with relevant output elasticity equals to the impact rate on real GDP.

\section{CONCLUSION}

This article tries to figure out that the impact of Beijing's human capital investment growth for its economic growth through empirical analysis. According to the result of empirical analysis based on the relevant data from 1993 to 2013, it is indicated that Beijing's economic growth based on the common growth of its physical capital and human capital. Even though the impact of physical capital investment growth on Beijing's economic growth is greater than human capital, but from the current development trend, investment in human capital of Beijing for its role in promoting Beijing's economic growth will be larger than physical capital. For the reason that, it is necessary to maintain physical capital inputs and further increase human capital investment of Beijing, so as to ensure the steady of economic growth in the foreseeable future years and encourage rapid economic growth at the same time.

\section{REFERENCES}

[1] EHRLICH, I. 2009. The Mystery of Human Capital as Engine of Growth or Why the US Became the Economic Superpower in the $20^{\text {th }}$ Century. Ensayos Economics. 1(56): $41-93$.

[2] LI, H.Z. et al. 2010. Human Capital Measurement and Index Construction in China. Journal of Economic Research. 8: 42 - 54. 
[3] LUCAS, R.E. 1988. On the Mechanics of Economic Development. Journal of Monetary Economics. 22(1): 342.

[4] ROMER, P.M. 1990. Human Capital and Growth: Theory and Evidence. Carnegie-Rochester Conference Series on Public Policy. 32(1): 251-286.

[5] SAVVIDES, A. et al. 2006. Economic Development and the Return to Human Capital: A Smooth Coefficient Semiparametric Approach. Journal of Applied Econometrics. 21(1): 111 - 132.
[6] TANG, X.J. 2006. Capital Deepening, Human Capital and Sustained Economic Growth in China. World Economy. 8: 57-64.

[7] WANG, J.Y. \& ZHENG, S.P. 2010. Comparison of Human Capital in the East and West of the role in Economic Growth. Population and Economy. 4: 24-30.

[8] YANG, J.F. et al. 2006. The Formation of Human Capital and Its Impact on Economic Growth: An Endogenous Growth Model and Inspection Included Inputs of Education and Health. Management World. 5: 10-18. 